\title{
The Orientation and Practice of Incentive Mechanism in Education Economic Management
}

\author{
Cui Yichu
}

Zhongnan University of Economics and Law, Wuhan, Hubei, 430073

Keywords: education; economic management; incentive mechanism

\begin{abstract}
With the development of the times, the education economy has become the most popular vocabularies in the current era, which mainly represents the economic content related to education. The main reason for its emergence is the current education industry, which can effectively drive the development of the national economy, especially the great benefits brought by education and scientific research, so that the state has to pay attention to it. Under such circumstances, the innovation and development of economic education management is a very important content. At present, it is necessary to use incentive mechanism to make education economic management develop better. But the incentive mechanism is not used in the education economic management, so it is necessary to start with the orientation of the incentive mechanism in the education economic management, and discuss how to better let the incentive mechanism in the educational economy manage play a greater effect. Starting from the specific contents of educational economic management, this paper will explore how to practice the incentive mechanism in educational economic management.
\end{abstract}

In the current era, economists and educators jointly put forward the concept of education economy. The education economy mainly refers to the economic behavior involved in education, such as R \& D, investment, profit and so on. To a certain extent, these behaviors can represent the development of education in the study area, and can make the relevant departments or schools make effective adjustments to promote the development of education in schools or regions. Therefore, the education economy is more important for the current education. But the time of education economy is short, our country is not able to manage the education economy better, which leads to the development of education economy is not comprehensive enough. In the current view, in order to better promote the development of education economy, it is necessary to carry out the introduction of incentive mechanism in the management of educational economy so as to make the education economy gain vitality. However, there is no precedent in the introduction of incentive mechanism in the economic management of education, so it is necessary to explore how to introduce incentive mechanism into the educational economy management.

\section{The specific content of the education and economic management}

In the specific contents of educational economic management, the first is the management of educational research funds. In the education industry, education and scientific research are ongoing. There are two main reasons: first, to adapt to the needs of the current era. In the present time, all theories in the world need to be constantly developed. If the theory is stagnant, it will be eliminated, which is the same as the human society, because people need various theories to continue to provide vitality to the development of society. At the same time, some of the previous theories will be gradually overthrown with the development of the times. For example, the famous Leaning Tower of Pisa iron ball experiment overthrew some theory of gravity related, so it can be seen that the theory is only right at a certain stage. Therefore, education and scientific research are constantly being carried out by countries all over the world. The second is the demand for the development of the country. Throughout history, the development of any country in the world is due to the development of its own science and technology. The development of science and technology can enable the country to gain more powerful economic strength and military strength, thus making it 
more powerful. Therefore, in this case, all countries are constantly carrying out education and scientific research. Based on this situation, the amount of educational research funds produced by a country is very huge every year, and the management of these educational research funds is one of the contents of the educational economic management[1].

At present, education is not free and cost free. The development of education will usually gain huge economic benefits for the education sector. These economic benefits are mainly reflected in two aspects: the first aspect is to provide the benefits of educational services. In the current view, although China has implemented nine years of compulsory education, but in addition to the tuition accident, there are many costs are not reduced, in this case, the annual economic income of the school is very considerable. In particular, colleges and universities, which take the self - fee education, only enjoy the subsidies of some countries, in this case, the income of education services in Colleges and universities is very huge. This is the first content of the income of the education economy. The second aspect is the benefits of scientific research in education. Although scientific research projects will produce a large amount of scientific research funds, but if some projects have been successfully studied and can be widely used, the income generated is very huge. These benefits include the cost of technology transfer, the cost of technology usage, and the dividends of products, which support the development of China's education economy. Therefore, educational economic returns are an important part of the management of educational economy.

\section{The orientation and practice path of incentive mechanism in education economic management}

In the economic management of education, the incentive mechanism should first be the incentive mechanism to promote the development of education. To a certain extent, the incentive mechanism is actually encouraging some good behaviors, including many aspects. Its main purpose is to better enable education to develop. The development of education has two advantages at present: first, it can improve the quality of the people. What is the quality of a nation's education and how the quality of its citizens will be directly proportional to the two? In order to make the development of education better, it is necessary to have a good management of the education economy, so that the education can get a lot of funds, thus better comprehensive development, which is very important for the educational cause. The second is to enhance the scientific and technological capabilities of the country. There are two contents in the development of education, which are related to the scientific and technological capabilities of the country. Education can cultivate a large number of talents, these talents themselves have professional scientific and technical knowledge, in the national scientific research and other projects, can be very effective, thus promoting the better development of China's scientific research projects, so that the country's scientific research strength can be greatly strengthened. The second item is the achievements of scientific research. The emergence of scientific research results is related to the development of educational undertakings, because the rapid development of educational undertakings can guarantee theoretical breakthroughs in a certain degree. These theories are the key to the success of scientific research projects. Therefore, the development of educational undertakings has indirectly promoted the emergence of new scientific research. To a certain extent, these scientific research success can represent the rise of national science and technology capability. It can be seen that the incentive mechanism in the education economic management should be one of the main purposes of promoting the development of education[2].

In the economic management of education, the orientation of incentive mechanism should be to promote the development of education economy. At present, the education economy mainly consists of three parts: first, the economic benefits brought by scientific research. The most important symbol of the development of education is the renewal of the theory, and the renewal of the general theory can promote the emergence of new scientific research results. These achievements can bring economic growth to a certain extent. Therefore, the economic benefits brought by scientific research are one of the important parts of the education economy. The second is the economic benefits brought by the education service. Education service is paid. This is a common concept, but 
people turn traditional goods into knowledge, and people buy new knowledge. So to a certain extent, people actually use the way of educational service to do business of knowledge. Therefore, the economic benefits brought by educational services can be regarded as the economic benefits of knowledge. Therefore, economic growth brought about by educational services is also an integral part of the education economy. Finally, it is the economic benefit that the talents bring. In education, a large number of talents are usually trained. The economic benefits that these talents can bring in the society are very considerable, but in general, these benefits are recessive and can not be directly embodied in education. But by conversion, people can know that economic growth comes from the use of talent, and that talent comes from education, so the growth of the economy can be converted into education, so that we can say that education can bring economic growth. These three parts can promote the progress of society and the economic benefit of the country to a certain extent. Therefore, the incentive mechanism in the management of educational economy should be regarded as one of its own positioning to promote the development of education economy. Only in this way can we ensure the development of our education economy, ensure the development of our national economy and ensure the strength of our country [3].

\section{The practical path of incentive mechanism in education economic management}

The first step in the practice of establishing an incentive mechanism in the economic management of education is to set up a special incentive fund for the growth of educational effects. At present, the special encouragement fund for educational effect growth should be divided into three parts: the first part is to give outstanding contributions to education and teaching. In the education economy, the workers of education and teaching are the core part. These people constitute the basic part of the whole education economy, and the work of these workers also makes the education economy develop better. For example, in a university, the number of talents trained by a teacher can be very huge, so the economic growth that the teacher can promote is also very huge, so the teacher trained the talent, and the talent created the economic growth, which can be said that the teacher indirectly promoted the growth of the economy. Those who make outstanding contributions to education and teaching should be encouraged. The second part is to make an important contributor to the improvement of education and teaching mode. At present, a scientific and reasonable education and teaching mode can cultivate more talents, and it is also widely used throughout the world. Therefore, the contributors who can effectively improve the educational and teaching models can create greater economic benefits. Therefore, it is necessary to affirm and promote the encouragement fund so that people can better study the improvement of education and teaching models. The third part is the reward for individual outstanding contributors in education and teaching. Not everyone is suitable for education, nor is everyone suitable for research and education. But a lot of people are suitable for the work of scientific research projects, in this case, these talents can create a large number of scientific research success, which can lead to the growth of the economy. Such talents should also be encouraged and commended[6].

The second step is to set up a special fund for the development of education and economy. The composition of its fund should be divided into two parts at present: the first part is to give outstanding contributors to the development of education and economy. In the development of the educational economy, people need to be guided. These people are generally the administrators of the education department. If they make a management decision that is beneficial to the development of the school, it can make the school better and promote the development of the education economy, because this part of the people is encouraged to encourage the development of the education economy. And commendation, so that we can ensure the all-round development of the education economy. The second part deals with the contributors of indirect education and economic development. There are many factors affecting the development of education economy. For example, political factors, in the state of political and political unrest, the country's education development will not be very good; for example, economic factors, in the state of poverty, the state's education development will also be very limited. Under such circumstances, some workers who can provide a stable environment for the development of education economy are also the main 
object of encouragement in the development of education economy. Without the efforts of these workers, the development of education and economy will be greatly hindered [4].

In the time path of encouraging the mechanism in the education economic management, the last step is to set up the effective use of the education economy and turn to the encouragement fund. The part of the fund has two parts: first, individuals, in the education economy, if individuals can convert some of the content of education into more educational economy, it will be able to promote the development of the education economy, which needs to be encouraged. The next is the organization. In the educational economy, it includes economic investment. If schools or some organizations can turn these investments into more talents or scientific research results, it is also necessary to encourage them[5].

\section{Conclusion}

Education economy is a concept of integration in many fields, such as economy, education, management and so on. This concept can explain the economic behavior in education to a certain extent. Therefore, it has become one of the most popular ideas in the current education industry, and is also one of the main ideas in the construction of most schools. But at present, most schools are not good enough for the application of educational economy and educational economic management. In this case, it is necessary for colleges and universities to find out the problems and improve them. At present, the orientation of the incentive mechanism in the educational economic management should be as follows: promoting the development of education and promoting the development of educational economy. In view of these two positions, the practice path of incentive mechanism in educational economic management should be divided into three points as following: adding special encouragement fund for the increase of educational effect, adding special encouragement fund for the development of educational economy, and adding special encouragement fund for the effective use of educational economy. This can ensure the rapid development of the education economy in China, thus promote the development of the education industry, bring economic growth for our country, and bring more high-quality talents. This is of vital importance to our country. At the same time, the introduction of incentive mechanism in educational economic management is also a practical content in the management of educational economy. It is one of the key elements to promote the development of educational economic management concept, and is also an important step to promote the development of education economy in China. Based on this situation, the Education Department of our country actively advocates such behavior, and gives a series of preferential policies, hoping that universities and local education can do a good job in the development of education economy.

\section{References}

[1] Han X. Private Colleges Market-Oriented Incentive Mechanism of Teacher Compensation Characteristics Research[C]// International Conference on Social Science and Higher Education. 2016.

[2] Han X. Private Colleges Market-Oriented Incentive Mechanism of Teacher Compensation Characteristics Research[C]// International Conference on Social Science and Higher Education. 2016.

[3] Ma J, Ma Z, Li J. An IPD-based incentive mechanism to eliminate change orders in construction projects in China [J]. Ksce Journal of Civil Engineering, 2017, 21(7):1-13.

[4] Zhao T, Department P, Amp N V. Research on Evaluation and Incentive Mechanism of Teachers' Enterprise Practice in Higher Vocational Colleges [J]. Journal of Nantong Vocational \& Technical Shipping College, 2017.

[5] Tang M Q, Yin W Q, Mu-Ye M A, et al. Pathway analysis on rural doctor's incentive mechanism[J]. Chinese Journal of Health Policy, 2016. 
[6] Wang Y, Vasilakos A V, Ma J. VPEF: A Simple and Effective Incentive Mechanism in Community-Based Autonomous Networks [J]. IEEE Transactions on Network \& Service Management, 2017, 12(1):75-86. 